\title{
Nhân tố ảnh hưởng đến cấu trúc vốn của các công ty sản xuất thương mại Việt Nam
}

\section{Factors influencing capital structure of Vietnam dealers and manufacturers}

\author{
Nguyễn Thị Thúy Hạnh ${ }^{1 *}$ \\ ${ }^{1}$ Trường Đại học Đà Nẵng - Phân hiệu Kon Tum, Việt Nam \\ "Tác giả liên hệ, Email: ntthanh296@ gmail.com
}

\section{THÔNG TIN}

DOI: $10.46223 / \mathrm{HCMCOUJS}$

econ.vi.14.1.508.2019

Ngày nhận: 19/10/2018

Ngày nhận lại: 30/11/2018

Duyệt đăng: 14/01/2019

\section{Tì khóa:}

cấu trúc vốn, doanh nghiệp, nhân tố ảnh hưởng, sản xuất thương mại, Việt Nam
Keywords:

capital structure, dealers and manufacturers, enterprises, influential factors, Vietnam
TÓM TẮT
Nghiên cứu phân tích các nhân tố ảnh hưởng đến cấu trúc vốn của các doanh nghiệp sản xuất thương mại Việt Nam. Số liệu nghiên cứu sử dụng dữ liệu thứ cấp từ các báo cáo tài chính hàng năm từ năm 2009 đến năm 2016 của 38 công ty sản xuất thương mại ở 2 sàn giao dịch chứng khoán ở Việt Nam là HOSE và $H N X$. Sử dụng eviews để phân tích dữ liệu bảng với tác động cố định, kết quả đã cho thấy qui mô, tài sản cố định, thanh khoản và sở hữu nhà nước có ảnh hưởng đến cấu trúc vốn của các doanh nghiệp sản xuất thương mại niêm yết Việt Nam. Kết quả thực nghiệm cho thấy qui mô và tài sản cố định có ảnh hưởng cùng chiều đến cấu trúc vốn trong khi thanh khoản và sở hữu nhà nước ảnh hưởng ngược chiều đến cấu trúc vốn.

\section{ABSTRACT}

This study identifies factors that influence the capital structure of dealers and manufacturers in Vietnam. The research data contain secondary data from the annual financial statements of 38 dealers and manufacturers on two Vietnam stock exchanges, HOSE and HNX over the period from 2009 to 2016. EViews is used to analyze a panel data with fixed effects, and the results show that size, fixed assests, liquidity and state ownership that influence the capital structure of trading produce companies in Vietnam. The empirical results show that the size and fixed assets have a positive relationship with capital structure while liquidity and state ownership have a negative relationship with capital structure. 


\section{1. Đặt vấn đề}

Cấu trúc vốn là sự kết hợp giữa nợ phải trả và vốn chủ sở hữu mà một doanh nghiệp sử dụng để tài trợ cho tài sản, hoạt động hàng ngày và dự án đầu tư. Quyết định cấu trúc vốn là một trong những quyết định quan trọng nhất của doanh nghiệp. Bất kỳ doanh nghiệp nào khi tiến hành các hoạt động sản xuất thương mại, mục tiêu hướng đến là tối đa hóa giá trị tài sản của chủ sở hữu. Để thực hiện mục tiêu này, doanh nghiệp cần thực hiện nhiều biện pháp trong đó việc lựa chọn một cấu trúc tài chính hợp lý và tối ưu là một trong những biện pháp quan trọng và cần thiết, là cơ sở cho việc đưa ra các quyết định chính xác Do (2018). Cấu trúc vốn tối ưu sẽ góp phần tối thiểu hóa chi phí sử dụng vốn và tăng giá trị doanh nghiệp.

Các nghiên cứu trước đây cũng đã tập trung phân tích các nhân tố ảnh hưởng đến cấu trúc vốn như lợi nhuận, quy mô công ty, tài sản cố định như K. T. D Nguyen và Ramachandran (2006), D. T. T. Nguyen, Diaz-Rainey, và Gregoriou (2012), Ahmad, Salman, và Shamsi (2015), Shamaileh và Khanfar (2014) và V. X. Vo (2017). Trên thực tế, cấu trúc vốn sẽ thay đổi tùy thuộc vào đặc điểm tình hình của từng doanh nghiệp, lĩnh vực mà doanh nghiệp hoạt động cũng như các ảnh hưởng từ sự biến động vĩ mô của nền kinh tế, các yếu tố văn hóa, tôn giáo. Chính vì thế, nghiên cứu những nhân tố ảnh hưởng đến cấu trúc vốn của doanh nghiệp ở từng lĩnh vực khác nhau là rất cần thiết. Ở Việt Nam đã có rất nhiều nghiên cứu tập trung vào từng lĩnh vực kinh doanh như doanh nghiệp xi măng, công nghiệp, du lịch, xây dựng, khoáng sản... C. T. Nguyen (2011); Vu và Nguyen (2013); P. T. M. Le (2014); Phan (2016); H. T. T. Nguyen (2017) và Pham (2017). Tuy nhiên chưa có nghiên cứu cụ thể về doanh nghiệp thuộc nhóm ngành sản xuất thương mại. Hiện nay có 50 công ty thuộc nhóm ngành sản xuất thương mại niêm yết trên hai sàn chứng khoán Hose và Hnx. Giá trị vốn thị trường của ngành đạt 82.983 tỷ đồng và lớn thứ 9/25 nhóm ngành. Tỷ số nợ/tổng nguồn vốn và tỷ số nợ/vốn chủ sở hữu của ngành sản xuất thương mại đạt $57 \%$ và $133 \%$. (Cophieu68, 2018). Điều đó cho thấy, các công ty sản xuất thương mại sử dụng nhiều nợ trong cấu trúc vốn của mình.

Chính vì vậy, nghiên cứu này khám phá những nhân tố tác động đến cấu trúc vốn của công ty sản xuất thương mại trên thị trường chứng khoán Việt Nam. Sổ liệu nghiên cứu sử dụng dữ liệu thứ cấp từ các báo cáo tài chính hàng năm của các công ty từ năm 2009 đến năm 2016 của 38 công ty sản xuất thương mại thuộc 2 sàn giao dịch chứng khoán ở Việt Nam là HOSE và $\mathrm{HNX}$. Kết quả nghiên cứu sẽ đóng góp vào cơ sở lý thuyết và thực tiễn về cấu trúc tài chính và góp phần hỗ trợ quyết định vốn của nhà quản trị tài chính của công ty sản xuất thương mại.

\section{Cơ sở lí thuyết}

Hiện nay vẫn chưa có một khái niệm chính thức về cấu trúc vốn tuy nhiên về bản chất cấu trúc vốn được hiểu là mối quan hệ giữa nợ và vốn chủ sở hữu trong nguồn vốn của doanh nghiệp. Trong nghiên cứu này, cấu trúc vốn được hiểu là tỷ lệ tổng nợ trên tổng tài sản của doanh nghiệp.

Lý thuyết cấu trúc vốn được đề cập đầu tiên là lý thuyết của Modigliani và Miller (M\&M) trong các nghiên cứu năm 1958 và 1963 . Năm 1958, với giả định không có thuế thu nhập doanh nghiệp, $\mathrm{M} \& \mathrm{M}$ chứng minh rằng cấu trúc vốn không có ảnh hưởng gì đến giá trị của công ty hoặc công ty không có cách nào để gia tăng giá trị bằng cách thay đổi cấu trúc vốn. Năm 1963, M\&M đã đưa thuế thu nhập doanh nghiệp vào mô hình nghiên cứu, chỉ ra giá trị của công ty có vay nợ bằng giá trị của công ty không có vay nợ cộng với hiện giá của "lá chắn thuế”. Nhìn chung, M\&M đã chỉ ra tồn tại mối liên hệ giữa cấu trúc vốn và giá trị của doanh nghiệp. Tuy nhiên, thị trường vốn không hoàn hảo và luôn tồn tại chi phí đại diện. 
Chính vì thế, một số nghiên cứu đi sau đã đưa ra chi phí khốn khó tài chính và chi phí quản lý đại diện vào nghiên cứu. Lý thuyết lợi ích bù trừ được nghiên cứu đầu tiên bởi Kraus và Litzenberger (1973) và chỉ ra rằng giá trị thị trường của một công ty có vay nợ bằng giá trị của công ty khi không vay nợ, cộng với giá trị của lá chắn thuế trừ đi phần giá trị bằng thuế suất thuế thu nhập doanh nghiệp nhân với hiện giá của chi phí phá sản. Điều này cho thấy là lợi ích của lá chắn thuế sẽ được bù đắp các thiệt hại nếu việc phá sản xảy ra. Các nghiên cứu lý thuyết cấu trúc vốn đều cho thấy tồn tại một cấu trúc vốn tối ưu cho doanh nghiệp, ở cấu trúc vốn đó, lợi ích của lá chắn thuế bù trừ tốt nhất cho các thiệt hại mà việc gia tăng vay nợ mang lại như: chi phí khốn khó tài chính, chi phí đại diện.

Bên cạnh với các lý thuyết trên, một hướng tiếp cận khác cho rằng không tồn tại cấu trúc vốn tối ưu, mà chỉ ra một trật tự ưu tiên khi tài trợ các khoản đầu tư như sau: đầu tiên sử dụng lợi nhuận giữ lại, tiếp theo là vay nợ bên ngoài và cuối cùng là phát hành cổ phiếu. Ngoài các lý thuyết ở trên, còn có các lý thuyết cấu trúc vốn hiện đại khác như thuyết điều chỉnh thị trường, thuyết cơ cấu quản lý.

Các nhân tố ảnh hưởng đến cấu trúc vốn được các nhà nghiên cứu trên thế giới chỉ ra là quy mô, lợi nhuận, tài sản cố định, sở hữu nhà nước, tác động của thuế thu nhập doanh nghiệp và thanh khoản.

Nhân tố đầu tiên tác động đến cấu trúc vốn là quy mô của công ty. Quy mô công ty là một trong những nhân tố ảnh hưởng đến mức độ sử dụng nợ. Thông thường, công ty càng lớn thì sẽ có khả năng vay nhiều nợ hơn. Vì công ty lớn thường đa dạng ngành nghề kinh doanh và rủi ro thông tin bất đối xứng thấp hơn công ty nhỏ. Đa số kết quả nghiên cứu trước đây đều cho thấy quy mô công ty tác động cùng chiều đến đòn bẩy tài chính như Marete (2015); Alghusin (2015); Truong và Nguyen (2015); Phan (2016); H. T. T. Nguyen (2017). Dang và Quach (2014) sử dụng phương pháp ước lượng các yếu tố không ngẫu nhiên (FEM - Fixed Effect Model) với 10 nhân tố được đưa vào mô hình gồm có: Quy mô doanh nghiệp, khả năng sinh lợi của doanh nghiệp, sự tăng trưởng của doanh nghiệp, đặc điểm riêng của tài sản, tài sản cố định hữu hình, tính thanh khoản của tài sản, điều kiện của thị trường chứng khoán, thuế, điều kiện thị trường nợ. Dữ liệu được thu thập từ 180 công ty phi tài chính niêm yết trên HOSE trong giai đoạn 2010-2013. Kết quả cho thấy có 3 nhân tố tác động mạnh đến cấu trúc vốn của các doanh nghiệp trong giai đoạn này, đó là: quy mô doanh nghiệp, khả năng sinh lợi và thuế. Trong đó quy mô doanh nghiệp có tương quan cùng chiều, còn thuế có tương quan ngược chiều với cấu trúc vốn.

Nhân tố thứ hai được xác định là lợi nhuận của công ty. Các nghiên cứu đi trước cho thấy lợi nhuận tác động ngược chiều đến cấu trúc vốn của công ty. Alghusin (2015) điều tra các công ty ở sở giao dịch chứng khoán Amman giai đoạn 1995-2005 đã chỉ ra mối quan hệ tỷ lệ nghịch giữa lợi nhuận và đòn bẩy tài chính ở các công ty công nghiệp. Phan (2016) đã sử dụng phương pháp GMM để xác định hướng tác động của các nhân tố lên cấu trúc vốn của các doanh nghiệp công nghiệp Việt Nam thông qua mẫu nghiên cứu gồm 95 doanh nghiệp niêm yết tại Việt Nam giai đoạn 2007-2013. Kết quả cho thấy doanh nghiệp có quy mô càng lớn thì càng có xu hướng sử dụng nhiều vốn vay hơn trong tổng tài sản. Tiếp theo, nhân tố khả năng sinh lời, tài sản hữu hình, tính thanh khoản của tài sản có ảnh hưởng ngược chiều lên cấu trúc vốn của doanh nghiệp. H. T. T. Nguyen (2017) đã nghiên cứu 14 công ty du lịch ở 2 sàn giao dịch chứng khoán ở Việt Nam là HOSE và HNX từ năm 2009 đến năm 2015. Sử dụng mô hình hồi quy dữ liệu bảng với tác động cố định là các công ty, tác giả đã chỉ ra ba nhân tố ảnh hưởng đến đòn bẩy tài chính của các công ty du lịch, gồm quy mô, lợi nhuận và tài sản cố định. Kết quả chứng 
minh quy mô và tài sản cố định có mối tương quan cùng chiều với đòn bẩy tài chính, trong khi lợi nhuận có mối tương quan ngược chiều với đòn bẩy tài chính.

Nhân tố thứ ba là tài sản cố định. Tài sản cố định được sử dụng như tài sản đảm bảo trong quá trình vay vốn của công ty. Đa số kết quả nghiên cứu đều chỉ ra mối quan hệ cùng chiều giữa tài sản cố định và cấu trúc vốn Harc (2015) và Alghusin (2015) và $\mathrm{H}$. T. T. Nguyen (2017). Nghiên cứu tất cả các công ty Việt Nam trên sàn giao dịch chứng khoán Hồ Chí Minh năm 2006 đến 2015 của V. X. Vo (2017) đã chỉ ra mối quan hệ tỷ lệ thuận giữa đòn bẩy tài chính và tài sản cố định đồng thời cho thấy mối quan hệ tỷ lệ nghịch giữa tài sản cố định và đòn bẩy ngắn hạn và tỷ lệ thuận với đòn bẩy dài hạn. Công ty Việt Nam với tài sản cố định càng nhiều thì vay nợ dài hạn càng nhiều và vay nợ ngắn hạn càng ít. Tuy nhiên, tồn tại một vài nghiên cứu cho thấy mối quan hệ ngược chiều giữa tài sản cố định và cấu trúc vốn như Phan (2016). Nghiên cứu chỉ ra đối với các công ty công nghiệp, doanh nghiệp đầu tư tài sản cố định chủ yếu bằng lợi nhuận giữ lại hoặc gia tăng vốn chủ sở hữu, chứ không ưu tiên sử dụng từ những khoản vay. Điều này cho thấy, ngành nghề lĩnh vực khác nhau thì quyết định về cấu trúc vốn cũng khác nhau.

P. T. Le (2017) cho rằng sở hữu nhà nước chi phối tác động tiêu cực đến hiệu quả hoạt động của doanh nghiệp (DN) Việt Nam. Bên cạnh việc sở hữu nhà nước có tác động tích cực đến hiệu quả hoạt động của $\mathrm{DN}$ do lợi thế là các $\mathrm{DN}$ này được hỗ trợ các chính sách từ phía Chính phủ như khung pháp lý, thuế và tiếp cận được nguồn vốn dễ dàng hơn, nghiên cứu cũng cho thấy sở hữu nhà nước có ảnh hưởng tiêu cực đến hiệu quả hoạt động của DN do nhà quản trị không có động lực hoặc ít nỗ lực trong việc tạo ra giá trị cho cổ đông. Áp dụng mô hình GMM và FGLS, Phan (2016) chứng minh sở hữu nhà nước tác động cùng chiều và có mức ý nghĩa thống kê cao lên cấu trúc vốn của doanh nghiệp.

Thuế thu nhập doanh nghiệp là yếu tố vĩ mô tác động đến cấu trúc vốn của doanh nghiệp. Lý thuyết M\&M (1963) đã chỉ ra mối quan hệ giữa thuế thu nhập và cấu trúc vốn của doanh nghiệp. Nghiên cứu của A. T. T. Vo, Tran, Le, và Tran (2014) đã cho thấy thuế tác động thuận đến tỷ lệ nợ dài hạn. Trong những giai đoạn suy thoái, việc giảm thuế góp phần giảm bớt khó khăn và giúp doanh nghiệp vượt qua khủng hoảng. Dang và Quach (2014) chỉ ra thuế có tương quan ngược chiều với cấu trúc vốn. N. T. M. Le (2016) phân tích 17 doanh nghiệp ngành xi măng được niêm yết trên thị trường chứng khoán Việt Nam (HOSE và HNX) trong giai đoạn 2007-2013. Kết quả cho thấy lá chắn thuế có tác động ngược chiều với tỷ lệ nợ trên tổng tài sản và tỷ lệ nợ dài hạn trên tổng tài sản.

Nhân tố cuối cùng tác động đến cấu trúc vốn được đề cập đến là thanh khoản doanh nghiệp. V. X. Vo (2017) đã chỉ ra thanh khoản là một trong những vấn đề quan trọng quyết định đến sự thành công của doanh nghiệp Việt Nam. Nghiên cứu chỉ ra mối quan hệ tỷ lệ nghịch giữa thanh khoản với đòn bẩy ngắn hạn của doanh nghiệp. Phan (2016) cũng cho thấy thanh khoản tác động ngược chiều lên cấu trúc vốn của doanh nghiệp.

\section{Phương pháp và dữ liệu nghiên cứu}

\subsection{Phưong pháp nghiên cứu}

Để xem xét các nhân tố ảnh hưởng đến cấu trúc vốn, nghiên cứu sử dụng mô hình dưới đây:

$$
\begin{aligned}
\text { TDTA } i, t=\beta_{0}+\beta_{1} \times \mathrm{ROA}_{i, t}+\beta_{2} \times \mathrm{SIZE}_{i, t}+\beta_{3} \times \mathrm{FIXED}_{i, t}+\beta_{4} \times \mathrm{STATE}_{i, t} \\
+\beta_{5} \times \mathrm{ET}_{i, t}+\beta_{6} \times \mathrm{LIQ}_{i, t} \beta_{\mu i, t}+e_{i}
\end{aligned}
$$


trong đó $i$ là công ty $\mathrm{I}, t$ là năm thứ $\mathrm{t}, \beta_{\mathrm{o}}$ là hằng số của mô hình hồi quy, $\beta_{1}, \beta_{2}, \beta_{3}, \beta_{4}, \beta_{5}$, $\beta_{6}$ là hệ số bê ta của các biến ROA, SIZE và FIXED, STATE, ET, LIQ $\mu_{i, t}$ là sai số chéo và chuỗi thời gian kết hợp, $e_{i}$ là thành phần sai số chéo hay theo cá nhân.

Nghiên cứu chạy mô hình hồi quy dữ liệu bảng với tác động cố định là công ty để tìm hiểu tác động của lợi nhuận, quy mô và tài sản cố định, sở hữu nhà nước, thuế thu nhập doanh nghiệp và thanh khoản đến cấu trúc vốn của doanh nghiệp sản xuất thương mại.

Cấu trúc vốn được đo lường bằng nhiều chỉ tiêu khác nhau. Do đó, theo các nghiên cứu đi trước bài viết lựa chọn đo lường bằng hệ số nợ, cho biết bao nhiêu \% tổng tài sản của doanh nghiệp được tài trợ bởi nợ. Bên cạnh đó, nghiên cứu thu thập các biến độc lập từ các bài báo đi trước để chỉ ra những nhân tố ảnh hưởng đến cấu trúc vốn của công ty sản xuất thương mại Việt Nam.

\section{Bảng 1}

Mô tả biến nghiên cứu

\begin{tabular}{|c|c|c|c|c|}
\hline $\begin{array}{c}\text { Biến } \\
\text { nghiên } \\
\text { cứu }\end{array}$ & Ký hiệu & Công thức & $\begin{array}{l}\text { Mối quan hệ } \\
\text { với biến phụ } \\
\text { thuộc }\end{array}$ & Co' sở lý thuyết \\
\hline \multicolumn{5}{|c|}{ Biến phu thuộc } \\
\hline $\begin{array}{l}\text { Cấu trúc } \\
\text { vốn }\end{array}$ & TDTA & $\frac{\text { Tổng nọ̣ }}{\text { Tổng tài sản }}$ & & $\begin{array}{l}\text { Alghusin (2015); Phan } \\
\text { (2016); H. T. T. Nguyen } \\
\text { (2017); V. X. Vo (2017) }\end{array}$ \\
\hline \multicolumn{5}{|c|}{ Biến độc lập } \\
\hline $\begin{array}{l}\text { Quy mô } \\
\text { công ty }\end{array}$ & SIZE & log (doanh thu thuần) & + & $\begin{array}{l}\text { Phan (2016); H. T. T. } \\
\text { Nguyen (2017) }\end{array}$ \\
\hline Lợi nhuận & ROA & $\frac{\text { Lợi nhuận sau thuế }}{\text { Tổng tài sẩn }}$ & - & $\begin{array}{l}\text { Alghusin (2015); Salman, } \\
\text { Ayo-Oyebiyi, và Emenike } \\
\text { (2015); Phan (2016); H. T. } \\
\text { T. Nguyen (2017) và V. X. } \\
\text { Vo (2017) }\end{array}$ \\
\hline $\begin{array}{l}\text { Tài sản } \\
\text { cố định }\end{array}$ & FIXED & $\frac{\text { Tài sản cố định }}{\text { Tổng tài sản }}$ & $+/-$ & $\begin{array}{l}\text { Phan (2016); H. T. T. } \\
\text { Nguyen (2017) và V. X. Vo } \\
(2017)\end{array}$ \\
\hline $\begin{array}{l}\text { Sở hữu } \\
\text { nhà nước }\end{array}$ & STATE & $\begin{array}{c}\text { Biến giả bằng } 1 \text { nếu nhà nước } \\
\text { chiếm hơn } 50 \% \text { vốn cồ phần và } \\
\text { bằng } 0 \text { trong các trường hợp còn lại }\end{array}$ & + & Phan (2016); P. T. Le (2017) \\
\hline $\begin{array}{l}\text { Thuế thu } \\
\text { nhập } \\
\text { doanh } \\
\text { nghiệp }\end{array}$ & ET & $\frac{\text { Thuế Thu nhập doanh nghiệp }}{\text { Tổng thu nhập trước thuế }}$ & - & $\begin{array}{l}\text { A. T. T. Vo và cộng sự } \\
\text { (2014); Dang và Quach } \\
\text { (2014); Phan (2016); N. T. } \\
\text { M. Le (2016) }\end{array}$ \\
\hline $\begin{array}{l}\text { Thanh } \\
\text { khoản }\end{array}$ & LIQ & Log $\frac{\text { Tài sản ngẳn hạn }}{\text { Nợ ngẳn hạn }}$ & $-/+$ & $\begin{array}{l}\text { Phan (2016); V. X. Vo } \\
(2017)\end{array}$ \\
\hline
\end{tabular}

Nguồn: Kết quả phân tích dữ liệu của nhóm nghiên cứu 


\subsection{Dũ liệu nghiên cúu}

Dữ liệu được thu thập từ 38 công ty cổ phần được niêm yết trên sàn giao dịch chứng khoán Hồ Chí Minh (HOSE) và sàn giao dịch chứng khoán Hà Nội (HNX) từ ngày 1/1/2009 đến $31 / 12 / 2016$. Số liệu được thu thập từ báo cáo tài chính hàng năm của công ty, gồm có tổng tài sản, lợi nhuận sau thuế, tổng nợ, tài sản cố định và doanh thu thuần, tỷ lệ sở hữu nhà nước, tài sản ngắn hạn, nợ ngắn hạn, thuế thu nhập doanh nghiệp, tổng thu nhập trước thuế của công ty.

\section{Kết quả nghiên cứu và thảo luận}

\subsection{Thống kê mô tả}

Bảng 2 cho thấy giá trị trung bình, số trung vị, giá trị lớn nhất, giá trị bé nhất, độ lệch chuẩn, độ lệch và độ nhọn của các biến nghiên cứu. Tổng số công ty nghiên cứu là 38 với 304 quan sát trong giai đoạn từ 2009 đến 2016.

\section{Bảng 2}

Thống kê mô tả

\begin{tabular}{|c|c|c|c|c|c|c|c|}
\hline & TDTA & ROA & SIZE & FIXED & STATE & LIQ & ET \\
\hline Giá trị trung bình & 0,450 & 0,077 & 5,599 & 0,221 & 0,259 & 0,257 & 0,096 \\
\hline Số trung vị & 0,458 & 0,147 & 5,640 & 0,199 & 0,000 & 0,227 & 0,071 \\
\hline Giá trị lớn nhất & 1,545 & 0,988 & 6,661 & 0,739 & 1,000 & 1,284 & 0,505 \\
\hline Giá trị bé nhất & 0,032 & $-73,01$ & 4,233 & 0,0004 & 0,000 & $-0,418$ & $-3,608$ \\
\hline Độ lệch chuẩn & 0,213 & 4,290 & 0,511 & 0,146 & 0,439 & 0,259 & 0,261 \\
\hline Độ nhọn & 0,489 & $-16,40$ & $-0,216$ & 0,984 & 1,095 & 0,909 & $-10,15$ \\
\hline Độ lệch & 4,512 & 279,148 & 2,328 & 3,926 & 2,199 & 4,480 & 139,097 \\
\hline $\mathrm{N}$ & 304 & 304 & 304 & 304 & 304 & 304 & 304 \\
\hline
\end{tabular}

Nguồn: Kết quả nghiên cứu của tác giả

\subsection{Ma trận tương quan}

Dựa vào Bảng 3 cho thấy ma trận tương quan giữa các biến nghiên cứu. Các nhân tố qui mô công ty, tài sản cố định và lợi nhuận có mối tương quan thuận với cấu trúc vốn trong khi các biến sở hữu nhà nước, thanh khoản và thuế thu nhập doanh nghiệp có mối tương quan nghịch.

\section{Bảng 3}

Ma trận tương quan

\begin{tabular}{|c|c|c|c|c|c|c|c|}
\hline & TDTA & ROA & SIZE & FIXED & STATE & LIQ & ET \\
\hline TDTA & 1,000 & 0,103 & 0,213 & 0,047 & $-0,032$ & $-0,747$ & $-0,114$ \\
\hline ROA & 0,103 & 1,000 & $-0,038$ & 0,111 & $-0,104$ & $-0,028$ & 0,007 \\
\hline SIZE & 0,213 & $-0,038$ & 1,000 & $-0,093$ & $-0,178$ & $-0,114$ & 0,137 \\
\hline FIXED & 0,047 & 0,111 & $-0,093$ & 1,000 & $-0,173$ & $-0,211$ & $-0,003$ \\
\hline STATE & $-0,032$ & $-0,104$ & $-0,178$ & $-0,173$ & 1,000 & 0,116 & $-0,013$ \\
\hline
\end{tabular}




\begin{tabular}{|c|c|c|c|c|c|c|c|}
\hline & TDTA & ROA & SIZE & FIXED & STATE & LIQ & ET \\
\hline LIQ & $-0,747$ & $-0,028$ & $-0,114$ & $-0,211$ & 0,116 & 1,000 & 0,106 \\
\hline ET & $-0,114$ & 0,007 & 0,137 & $-0,003$ & $-0,013$ & 0,106 & 1,000 \\
\hline
\end{tabular}

Nguồn: Kết quả nghiên cứu của tác giả

\subsection{Hệ số hồi quy}

Bảng 4 trình bày hệ số hồi qui của các biến nghiên cứu với tác động cố định. Giá trị $\mathrm{F}$ $=31,37$ và xác xuất (chuẩn $\mathrm{F}$ ) $<0,01$ cho thấy mô hình hồi qui có ý nghĩa. Bên cạnh đó, mô hình có $\mathrm{R} 2$ là 0,838 ; giá trị $\mathrm{R} 2$ rất cao. Điều này cho thấy $83,8 \%$ sự thay đổi của cấu trúc vốn được giải thích bởi biến độc lập.

Quy mô và tài sản cố định có mối quan hệ ngược chiều và có ý nghĩa với cấu trúc vốn trong khi sở hữu nhà nước và thanh khoản có nghĩa và mối quan hệ thuận chiều với cấu trúc vốn. Hai biến lợi nhuận và thuế thu nhập doanh nghiệp trong mô hình không có ý nghĩa thống kê. Điều này cho thấy các công ty có lợi nhuận cao thường sử dụng lợi nhuận giữ lại để tái đầu tư và kinh doanh chứ không đi vay bên ngoài. Các công ty sản xuất thương mại không đi vay để tận dụng lợi ích từ lá chắn thuế. Do đó, lý thuyết trật tự phân hạng phù hợp hơn các lý thuyết khác khi giải thích sự vận động của cấu trúc vốn của doanh nghiệp sản xuất thương mại Việt Nam.

Size có hệ số hồi quy là 0,109 và có ý nghĩa ở mức 5\%. Kết quả chứng minh cấu trúc tài chính và quy mô có mối quan hệ cùng chiều. Công ty có quy mô càng lớn thì xu hướng vay nợ nhiều hơn công ty nhỏ. Kết quả này phù hợp với giả thiết đã đưa ra và các nghiên cứu trước như Alghusin (2015); Phan (2016); H. T. T. Nguyen (2017).

Trong khi đó, Fixed có hệ số là 0,134 và có ý nghĩa ở mức $10 \%$. Kết quả cho thấy tài sản cố định có mối quan hệ cùng chiều với cấu trúc tài chính. Tài sản cố định được xem như tài sản bảo đảm thực do đó khi tài sản cố định càng cao thì sẽ tạo điều kiện cho doanh nghiệp vay nợ. Kết quả nghiên cứu phù hợp với nghiên cứu của H. T. T. Nguyen (2017) và V. X. Vo (2017).

Tiếp theo, State có hệ số là $-0,182$ và có ý nghĩa ở mức $10 \%$. Điều này cho thấy mối quan hệ tỷ lệ nghịch giữa cấu trúc vốn và sở hữu nhà nước. Kết quả nghiên cứu này khác với kết quả của Phan (2016) trong trường hợp với các công ty công nghiệp. Tổng số 38 công ty sản xuất thương mại trong đó 10 công ty do nhà nước sở hữu hơn $50 \%$, bình quân tổng nợ đạt 273.089 triệu đồng trong khi các công ty khác đạt bình quân hơn 285.097 triệu đồng. Do đó, những công ty có sở hữu nhà nước chiếm hơn $50 \%$ thì sử dụng nợ ít hơn công ty khác.

Cuối cùng Liq có hệ số -0.460 và có ý nghĩa ở mức $1 \%$, đây cũng là biến nghiên cứu có giá trị hệ số hồi qui cao nhất, điều đó cho thấy tác động của thanh khoản đến cấu trúc tài chính mạnh hơn các biến nghiên cứu khác. Kết quả thực nghiệm cho thấy, nhân tố này tác động ngược chiều lên cấu trúc vốn của doanh nghiệp Phan (2016). Đối với các công ty sản xuất thương mại, nợ ngắn hạn chiếm hơn $80 \%$ tổng nợ do đó kết quả này là hoàn toàn dễ hiểu. Doanh nghiệp giảm vay nợ thì sẽ làm cho thanh khoản cao lên. 


\section{Bảng 4}

Hệ số hồi quy

\begin{tabular}{|c|c|c|c|c|}
\hline Biến nghiên cứu & Hệ số & Sai số chuẩn & Chuẩn t & Xác suất \\
\hline C & $-0,028$ & 0,222 & $-0,126$ & 0,899 \\
\hline ROA & 0,001 & 0,001 & 1,291 & 0,197 \\
\hline SIZE & 0,109 & 0,038 & 2,862 & 0,004 \\
\hline FIXED & 0,134 & 0,071 & 1,891 & 0,059 \\
\hline STATE & $-0,182$ & 0,102 & $-1,782$ & 0,075 \\
\hline ET & 0,009 & 0,023 & 0,407 & 0,684 \\
\hline LIQ & $-0,460$ & 0,036 & $-12,48$ & 0,000 \\
\hline
\end{tabular}

Nguồn: Kết quả nghiên cứu của tác giả

\subsection{Một số kiểm định khác}

Để xem xét mô hình FEM hay REM phù hợp hơn, ta sử dụng kiểm định Hausman. Với giá trị $\mathrm{p}<0.01$ cho thấy sử dụng mô hình hồi quy với tác động cố định là phù hợp.

\section{Bảng 5}

Kiểm định Hausman

\begin{tabular}{|c|c|c|c|}
\hline Test Summary & Chi-Sq. Statistic & Chi-Sq. d.f. & Prob. \\
\hline Cross-section random & 24,00 & 6 & 0,00 \\
\hline
\end{tabular}

Nguồn: Kết quả nghiên cứu của tác giả

Bảng 6 và bảng 7 trình bày kết quả kiểm định phương sai sai số thay đổi. Kết quả cho thấy thống kê $\mathrm{F}$ có sig nhỏ hơn $1 \%$ nên bác bỏ Ho và cho thấy mô hình có hiện tượng phương sai sai số thay đổi.

\section{Bảng 6}

Kiểm định phương sai sai số thay đổi

\begin{tabular}{|c|c|c|c|}
\hline \multicolumn{5}{|c|}{ Heteroskedasticity Test: White } \\
\hline F-statistic & 4,27 & Prob. F(21.282) & 0,00 \\
\hline Obs*R-squared & 72,91 & Prob. Chi-Square(21) & 0,00 \\
\hline Scaled explained SS & 292,64 & Prob. Chi-Square(21) & 0,00 \\
\hline
\end{tabular}

Nguồn: Kết quả nghiên cứu của tác giả

\section{Bảng 7}

Kiểm định Breusch-Godfrey Serial Correlation

\begin{tabular}{|l|l|l|c|}
\hline F-statistic & 52,44 & Prob, F(2.296) & 0,00 \\
\hline Obs*R-squared & 79,49 & Prob, Chi-Square(2) & 0,00 \\
\hline
\end{tabular}

Nguồn: Kết quả nghiên cứu của tác giả 


\section{Kết luận}

Nghiên cứu phân tích các nhân tố ảnh hưởng đến cấu trúc vốn của các doanh nghiệp sản xuất thương mại Việt Nam trong giai đoạn 2009-2016. Sử dụng eviews để phân tích dữ liệu bảng với tác động cố định, kết quả đã cho thấy qui mô, tài sản, thanh khoản và sở hữu nhà nước có ảnh hưởng đến cấu trúc vốn của các doanh nghiệp sản xuất thương mại niêm yết Việt Nam.

Hầu hết các nghiên cứu thực nghiệm ở Việt Nam đều cho thấy nhân tố qui mô có ảnh hưởng cùng chiều lên cấu trúc vốn của doanh nghiệp, đây cũng là thực trạng chung cho tình hình cấu trúc vốn của các doanh nghiệp Việt Nam. Doanh nghiệp có qui mô càng lớn thì có xu hướng sử dụng nhiều vốn vay hơn. Bên cạnh đó, nhân tố tài sản cố định cũng cho thấy tác động cùng chiều đến cấu trúc vốn. Tài sản cố định là tài sản đảm bảo thực đối với chủ nợ và ngân hàng.

Tiếp theo, kết quả thực nghiệm cho thấy nhân tố sở hữu nhà nước có tác động ngược chiều đến cấu trúc vốn. Đối với các công ty sản xuất thương mại, công ty có vốn sở hữu nhà nước lớn hơn $50 \%$ thì sử dụng tổng nợ bình quân thấp hơn các công ty có vốn sở hữu nhà nước thấp hơn $50 \%$ hoặc không có sở hữu nhà nước. Về tính thanh khoản của tài sản, kết quả thực nghiệm cho thấy, nhân tố này tác động ngược chiều lên cấu trúc vốn của doanh nghiệp và có mức tác động mạnh nhất trong các nhân tố. Kết hợp với thực trạng rằng trong cơ cấu nợ của các doanh nghiệp sản xuất thương mại Việt Nam, tỷ lệ nợ ngắn hạn chiếm đến hơn $80 \%$ tổng nợ do đó với tài sản ngắn hạn không đổi, thì doanh nghiệp giảm vay nợ sẽ làm tính thanh khoản của doanh nghiệp tăng lên. Kết luận này được ủng hộ bởi rất nhiều các nghiên cứu thực nghiệm khác trước đây. Ngoài những yếu tố trên, các yếu tố còn lại đều không cho ý nghĩa thống kê trong ảnh hưởng đến cấu trúc vốn của các doanh nghiệp sản xuất thương mại Việt Nam.

Nghiên cứu cung cấp thêm trường hợp điển hình làm rõ hơn cơ sở lý luận cấu trúc tài chính ở Việt Nam, cụ thể về các nhân tố tác động và mức độ ảnh hưởng của các nhân tố đối với trường hợp công ty sản xuất thương mại. Kết quả này rất hữu ích đối với các nhà quản lý tài chính, nhà đầu tư và nhà tài trợ đối với trường hợp công ty sản xuất thương mại Việt Nam. Những bằng chứng thực nghiệm của nghiên cứu sẽ có ngụ ý quan trọng đối với các nhà hoạch định chính sách tài chính của công ty về nhận diện và quản trị chính sách tài trợ. Công ty sản xuất thương mại ưu tiên sử dụng lợi nhuận giữ lại hay nguồn vốn chủ sở hữu hơn đi vay. Bên cạnh đó, kết quả nghiên cứu chỉ ra công ty chủ yếu vay để đầu tư tài sản cố định. Tuy nhiên, tài sản cố định nhỏ hơn tài sản ngắn hạn do đặc thù của ngành, đầu tư vào hàng tồn kho chiếm tỷ trọng lớn. Điều đó cho thấy công ty sử dụng nguồn vốn bên trong để tài trợ nợ ngắn hạn.

\section{Tài liệu tham khảo}

Ahmad, N., Salman, A., \& Shamsi, A. F. (2015). Impact of financial leverage on firms' profitability: An investigation from cement sector of Pakistan. Research Journal of Finance and Accounting, 6(7), 75-80.

Alghusin, N. A. S. (2015). Do financial leverage, growth and size affect profitability of jordanian industrial firms listed? International Journal of Academic Research in Business and Social Sciences, 5(4), 335-348. 
Cophieu68. (2018). Tăng trương tài chính ngành [Industry financial growth]. Retrieved October 20, 2017, from Cổ phiếu 68 website: http://www.cophieu68.vn/categorylist.php?o=cm\&ud=d

Dang, Q. T., \& Quach, Y. T. H. (2014). Các nhân tố tác động đến cấu trúc vốn của doanh nghiệp niêm yết trên Sở Giao dịch Chứng khoán TP.HCM (HOSE) [Factors affecting the capital structure of businesses listed on the Ho Chi Minh City Stock Exchange (HOSE)]. Tap chi Phát triển \& Hội nhập, 18(28), 34-39.

Do, L. T. (2018). Nghiên cứu các nhân tố ảnh hương đến cấu trúc tài chính của doanh nghiệp [Research on factors affecting the financial structure of the business]. Retrieved October 25, 2017, from http://vaa.net.vn/nghien-cuu-cac-nhan-to-anh-huong-den-cau-truc-taichinh-cua-doanh-nghiep/

Harc, M. (2015). The relationship between tangible assets and capital structure of small and medium-sized companies in Croatia. Ekonomski Vjesnik, 28(1), 213-224.

Kraus, A., \& Litzenberger, R. H. (1973). A state-preference model of optimal financial leverage. The Journal of Finance, 28(4), 911-922.

Le, N. T. M. (2016). Các yếu tố tác động đến cấu trúc vốn: Một nghiên cứu trong ngành xi măng Việt Nam [Factors affecting capital structure: A study in the cement industry in Vietnam]. Van Hien University Journal of Science, 4(3), 30-37.

Le, P. T. (2017). Tác động cấu trúc sở hũu đến hiệu quả hoạt động của doanh nghiệp niêm yết [Ownership structure impact on the performance of a listed company]. Retrieved October 27, 2017, from http://tapchitaichinh.vn/nghien-cuu--trao-doi/trao-doi-binh-luan/nhan-toanh-huong-toi-cau-truc-von-cua-cac-cong-ty-nganh-xay-dung-niem-yet-tren-san-chungkhoan-88321.html

Le, P. T. M. (2014). Nhân tố ảnh hưởng tới cấu trúc vốn của các công ty ngành Xây dựng niêm yết trên sàn chứng khoán [Factors affecting capital structure of construction companies listed on the stock exchange]. Tạp chí Tài chính, 8, 23-30.

Marete, D. (2015). The relationship between firm size and financial leverage of firms listed at Nairobi securities exchange (Doctoral dissertation, University of Nairobi, Kenya).

Modigliani, F., \& Miller, M. H. (1958). The cost of capital, corporation finance and the theory of investment. The American Economic Review, 48(3), 261-297.

Modigliani, F., \& Miller, M. H. (1963). Corporate income taxes and the cost of capital: A correction. The American Economic Review, 53(3), 433-443.

Nguyen, C. T. (2011). Các nhân tố ảnh hưởng đến cấu trúc vốn của các doanh nghiệp chế biến thủy sản Việt Nam [Factors affecting capital structure of Vietnamese seafood processing enterprises]. Tạp chí Phát triển Khoa học và Công nghệ, 14(1), 28-54.

Nguyen, D. T. T., Diaz-Rainey, I., \& Gregoriou, A. (2012). Financial development and the determinants of capital structure in Vietnam. Retrieved October 5, 2017, from http://www.nzfc.ac.nz/archives/ 2013/papers/updated/46.pdf

Nguyen, H. T. T. (2017). Nhân tố tác động đến đòn bẩy tài chính của các Công ty Du Lịch Việt Nam [Factors affecting the financial leverage of Vietnam Travel Companies]. Tap chi Khoa hoc - Đại học Huế, 126(5A), 5-17. 
Nguyen, K. T. D., \& Ramachandran, N. (2006). Capital structure in small and medium-sized enterprises: The case of Vietnam. ASEAN Economic Bulletin, 23(2), 192-211.

Pham, L. T. D. (2017). Các yếu tố ảnh hưởng đến cấu trúc vốn của doanh nghiệp nhà nước sau cổ phần hóa trong thời kỳ hội nhập [Factors affecting the capital structure of state-owned enterprises after equitization in the integration period]. Retrieved May 5, 2017, from http://m.tapchicongthuong.vn/cac-yeu-to-anh-huong-den-cau-truc-von-cua-doanhnghiep-nha-nuoc-sau-co-phan-hoa-trong-thoi-ky-hoinhap20170322093432256p0c488.htm

Phan, H. T. (2016). Nhân tố ảnh huởng đến cấu trúc vốn của doanh nghiệp công nghiệp nhìn tù mô hìh GMM [Factors affecting the capital structure of industrial enterprises seen from the GMM model]. Retrieved May 10, 2017, from Tạp chí Tài chính website: http://tapchitaichinh.vn/tai-chinh-kinh-doanh/tai-chinh-doanh-nghiep/nhan-to-anhhuong-den-cau-truc-von-cua-doanh-nghiep-cong-nghiep-nhin-tu-mo-hinh-gmm85427.html

Salman, A. Y., Ayo-Oyebiyi, G. T., \& Emenike, O. A. (2015). Influence of financial inclusion on small and medium enterprises growth and development in Nigeria. International Journal in Management and Social Science, 3(4), 390-401.

Shamaileh, M. O., \& Khanfar, S. M. (2014). The effect of the financial leverage on the profitability in the tourism companies (analytical study-tourism sector-Jordan). Business and Economic Research, 4(2), 251-264.

Truong, T. H., \& Nguyen, P. T. (2015). Effects of financial crisis on capital structure of listed firms in Vietnam. International Journal of Financial Research, 7(1), 66-74.

Vo, A. T. T., Tran, L. K., Le, A. T. N., \& Tran, D. T. (2014). Nghiên cứu tác động của các nhân tố vĩ mô đến cấu trúc vốn của các công ty niêm yết trên thị trường chứng khoán Việt Nam [Studying the impact of macro factors on capital structure of companies listed on Vietnam's stock market]. Tạp chí Kinh tế và Phát triển, 207, 19-27.

Vo, V. X. (2017). Determinants of capital structure in emerging markets: Evidence from Vietnam. Researh in International Business and Finance, 40, 105-113.

Vu, L. T. N., \& Nguyen, D. T. (2013). Các nhân tố ảnh hưởng tới cấu trúc vốn của các Doanh nghiệp tại Tập đoàn Dầu khí Việt Nam [Factors affecting the capital structure of enterprises in the Vietnam Oil and Gas Group]. Tạp chí Kinh tế và Phát triển, 193, 2328. 